\title{
Influence of Single-Phase Solar Photovoltaic Systems on Total Harmonic Distortion: A Case Study
}

\author{
Chin Kim Gan, Sara Ragab Mahmoud, Kyairul Azmi Baharin, Mohd Hendra Hairi \\ Energy and Power Systems Research Group - CeRIA, Fakulti Kejuruteraan Elektrik, Universiti Teknikal Malaysia \\ Melaka, Jalan Hang Tuah Jaya, 76100 Durian Tunggal, Melaka Malaysia
}

\begin{tabular}{l} 
Article Info \\
\hline Article history: \\
Received May 14, 2018 \\
Revised Jul 15, 2018 \\
Accepted Jul 19, 2018 \\
\hline
\end{tabular}

Keywords:

Power quality

Solar photovoltaic system

Total harmonic distortion

\begin{abstract}
The installation of small-scale solar photovoltaic system has recently gaining popularity in Malaysia mainly driven by the Feed-in Tariff scheme. Given its relatively small generation capacity, the single-phase solar inverters are not required to comply with power quality standard. Neverthelss, the impact of small-scale solar system on the grid could become significant when the penetration is increasing over the years. In this regard, this paper presents a case study on the influence of single-phase grid-connected solar photovoltaic systems on the total harmonic distortion for current at the point of common coupling. Field measurements have been carried out for a total of 12 singlephase solar systems which were installed at three different locations at Universiti Teknikal Malaysia Melaka. Detailed analyses have been performed to characterize the aggregated current harmonic performance for the overall system. The findings from the presented case study suggest that the current quality from the inverter is highly dependent on the level of inverter output. Hence, the proper selection of the array-to-inverter ratio at the system design stage could greatly improve the overall total harmonic performance performance for current.
\end{abstract}

Copyright (C) 2018 Institute of Advanced Engineering and Science. All rights reserved.

Corresponding Author:

Chin Kim Gan,

Energy and Power Systems Research Group - CeRIA,

Fakulti Kejuruteraan Elektrik, Universiti Teknikal Malaysia Melaka,

Jalan Hang Tuah Jaya, 76100 Durian Tunggal, Melaka, Malaysia.

Email: ckgan@utem.edu.my

\section{INTRODUCTION}

Malaysia has witnessed the widespread installation of small-scale solar photovoltaic system at the low voltage distribution network. This is primarily driven by the Feed-in Tariff incentive scheme of which the solar investor will get paid at the premium rate for the solar energy exported to the grid [1]. Nevertheless, such installation will introduce new technical challenges to the existing grid, such as power quality, reversed power flow and network protection issues [2]. The field measurement results of power quality characterization for residential solar photovoltaic (PV) system is presented in [3]-[4] for one single system. As expected, the current quality is highly dependent on the inverter's operating conditions. Field results from [5] illustrate that voltage distortion from the solar PV system is not a main concern and is almost negligible. However, network simulation has shown that voltage rise could be a potential issue in the network with high PV generation [6]. Furthermore, modelling of the impact of grid-connected inverter on low voltage network has been addressed in [7]-[8] and similar conclusions have been drawn from those field measurement.

In Malaysia, the maximum allowable total harmonic distortion (THD) current for the inverter connected at medium voltage must be less than or equal to $5 \%$ at not more than $50 \%$ of the rated inverter output [9]. The PV system of greater than $425 \mathrm{kWp}$ is normally considered for medium voltage connection. Given the relatively small capacity, the few kilo-watt single-phase inverters are not subjected to this 5\% THD 
requirement. Nonetheless, the impact of small-scale solar system on the grid could become significant when the penetration is increasing over the years. Therefore, this paper focuses on the influence of single-phase solar PV system on total harmonic distortion for current. Actual field measurements have been carried out on 12 single-phase inverters connected at the same point of common coupling. This enables the analysis of the performance of aggregated current THD for multiple single-phase PV systems installed at different locations to be carried out. This paper has proposed the array-to-inverter ratio as one of PV system design consideration in achieving higher THD current performance.

The next section of the paper will describe the PV systems under study, followed by the analysis and discussion of the collected field measurement data. Finally, the paper is concluded with the key findings of this work.

\section{METHODOLOGY}

The Faculty of Electrical Engineering (FKE), Universiti Teknikal Malaysia Melaka has installed four different grid-connected solar PV systems with four different module technologies, namely monocrystalline, poly-crystalline, thin-fim and heterojunction technologies. Each of the systems is equipped with three units of $2 \mathrm{~kW}$ single-phase inverter. The PV rating and the array-to-inverter ratio of each systems are as shown in Table 1 below. As can be seen in the table, the total installed PV capacity is $23.88 \mathrm{~kW}_{\mathrm{p}}$. The installation method for all of the four PV systems is free standing with different azimuth angle (from south to south-east). In addition, the outputs of these four PV systems are terminating at the same point of common coupling (PCC). The fields measurements in this case study were taken at this point of common coupling as shown in Figure 1. The measurement device that has been installed at the PCC is SIEMENS SENTRON PAC4200 energy power meter. It is also important to note that the connection of the 12 singlephase inverters to the main grid was arranged in the balanced manner. Therefore, any imbalance ocurrued in the system is caused by the external factors such as temperature, shading, module mismatch, weather conditions and etc.

Table 1. PV array capacity and array-to-inverter ratio

\begin{tabular}{lccc}
\hline System & Module rated capacity $\left(\mathrm{W}_{\mathrm{p}}\right)$ & PV array capacity $\left(\mathrm{kW}_{\mathrm{p}}\right)$ & Array-to-inverter ratio \\
\hline Mono-crystalline & 255 & 6.12 & 1.02 \\
Poly-crystalline & 245 & 5.88 & 0.98 \\
Thin-film & 130 & 6.24 & 1.04 \\
Heterojunction & 235 & 5.64 & 0.94 \\
Total & $\mathrm{n} / \mathrm{a}$ & 23.88 & 0.995 \\
\hline
\end{tabular}

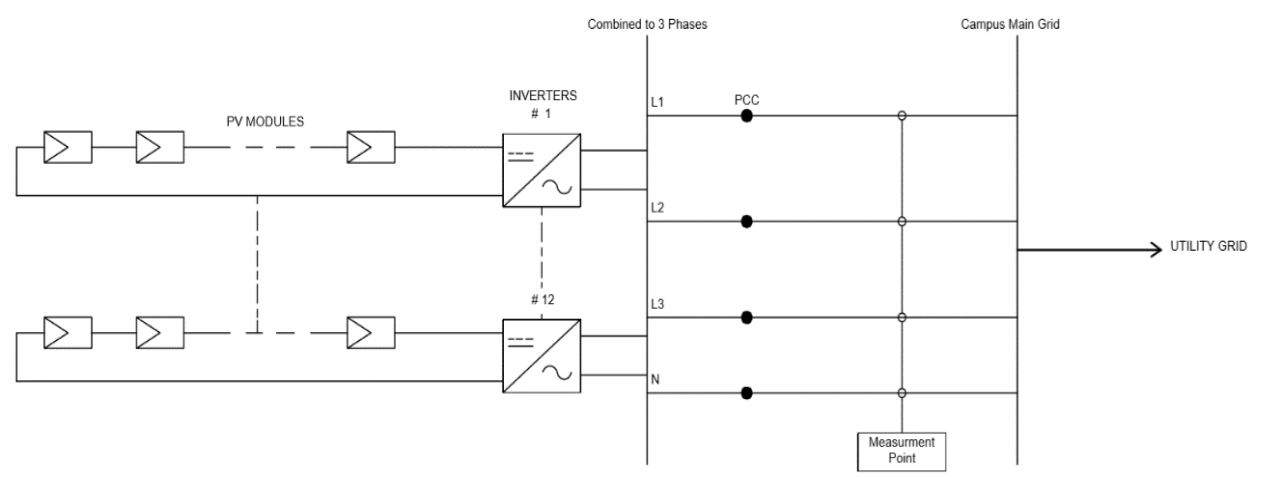

Figure 1. Schematic diagram for the solar system

\section{RESULTS AND ANALYSIS}

Figure 2 shows the actual solar generation profile in one-second time resolution recorded on 24 May 2018 at the point of common coupling for the on-grid solar system installed at FKE, UTeM. The solar generation is indicated as negative load since it is injecting power from the consumer side. As discussed earlier, the total installed capacity for the four (4) distributed solar PV systems in UTeM is approximately $24 \mathrm{kWp}$. Assuming $15 \%$ of total solar system losses, the corresponding peak generation would be $20.4 \mathrm{~kW}$ under $1000 \mathrm{~W} / \mathrm{m}^{2}$ of irradiance. This is inline with the recorded peak generation of $20.5 \mathrm{~kW}$ at 13.10 hour as 
shown in Figure 2 below. In addition, the figure clearly shows the intermittency of the solar generation profile caused by the moving clouds, which is representative of the cloudy weather condition in Malaysia.

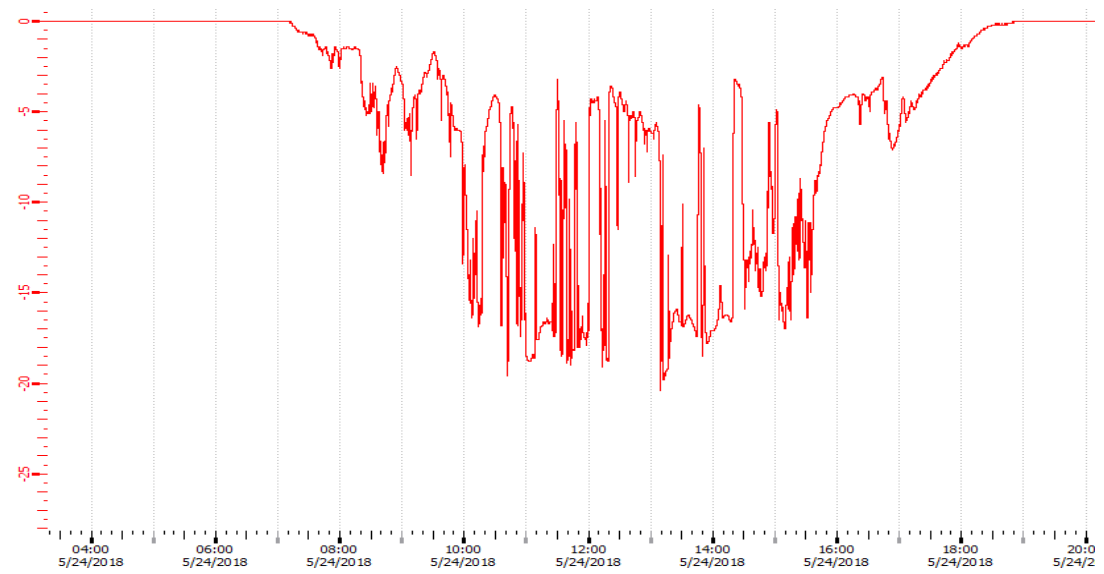

Figure 2. Actual solar generation profile on 24 May 2018 at FKE, UTeM

The maximum total harmonic factor of less than 5\% reported in the three phase solar inverter's datasheet is often referred to the rated inverter AC output [10]. Nevertheless, it is not common for the manufacturer to declare THD specification for single-phase inverter in the datasheet. Hence, it would be interesting to observe the THD performance of the single phase solar inverter under the actual weather conditions. Figure 3 shows the total current harmonic distortion at the point of common coupling for all the three phases. It can be seen from Figure 3 that there are two instances that the current THD perform poorly, i.e. during morning start-up and evening shutdown of the solar inverter. During the start-up of the inverter (7:15am in Fiugre 3), the current THD can rise to as much as over 50\%, and subside gradually as the solar irradiance increases. It can be further observed that as the solar irradiance decreases in the evening, the current THD will start to increase rapidly and reach its maximum value before the shutting down on the inverter. Current THD of 60\% was recorded on 6:50pm at L1 as shown in Figure 3.

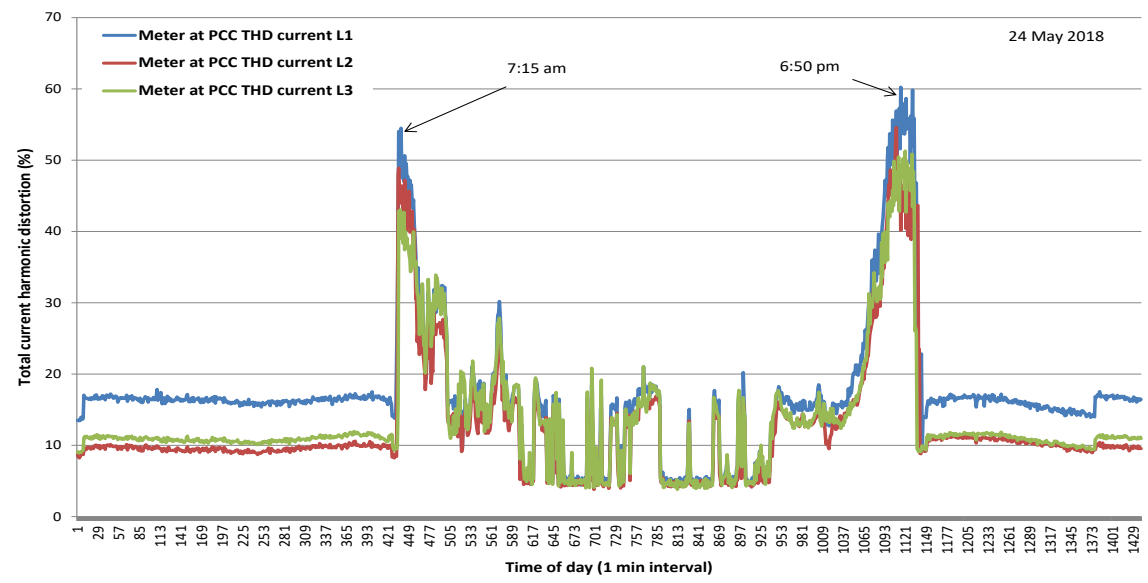

Figure 3. Total current harmonic distortion recorded on 24 May 2018

The zoom up of the one-hour duration (7:00 am - 8:00 am) plot for current THD using the high quality one-second interval data is as shown in Figure 4. As can be seen from the figure, the variability of the THD is very high; this may due to the high switching frequency in the solar inverter, coupled with the intermittency from the solar irradiance. Hence, it could be of specific interest to look into the mitigation methods on solar inverter to improve its current THD performance, particularly during the morning starting- 
up and evening shutting-down of the inverter. In addition, it is also interesting to note the unbalance THD amongst the three phases, primarily caused by the external factors such as the passing clouds and potential partial shading.

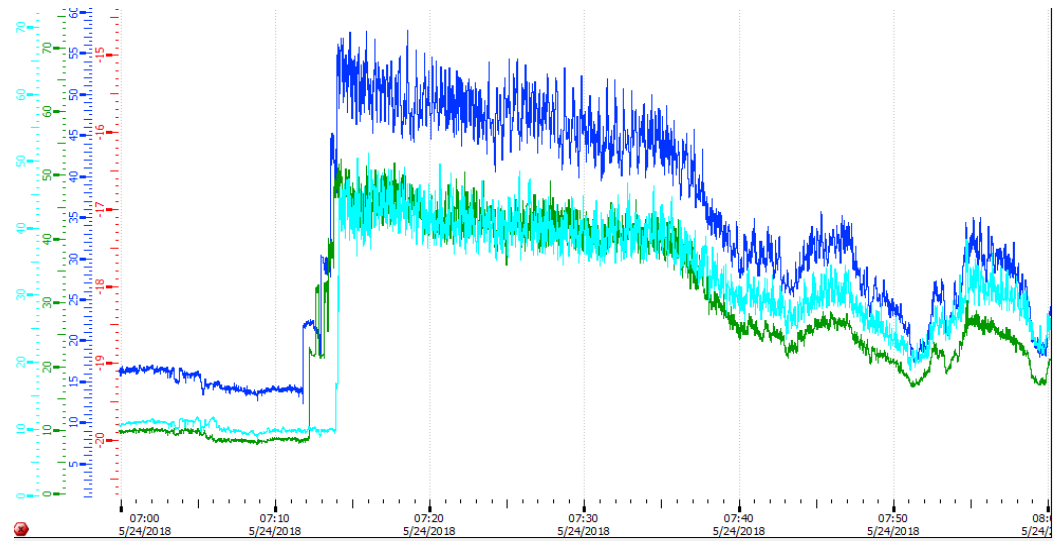

Figure 4. One-hour zoom up for current total harmonic distortion from 7am to $8 \mathrm{am}$

Figure 5 shows the total solar generation output expressed as the ratio of the total inverter rated AC power ratio measured at the point of common coupling for three (3) different days. Data considered were from 7:30 am to 7:30 pm at one minute interval for all the three phases. It is interesting to observe the nonlinearity of the current THD performance with regard to the inverter output (implicity solar irradiance level). The current THD of over $40 \%$ is mainly contributed from the 1 hour morning inverter starts up and 1 hour evening inverter shut down periods. Generally, the THD improves when the output of the inverter increases (irradiance dependent). It is also important to note that the current THD stablise at the range of between $4 \%$ $6 \%$ when the solar output at the point of common coupling is over $60 \%$ of the aggregrated solar inverter capacity. This implies the importance of the optimal selection of array-to-inverter ratio to achieve better harmonic performance in the system. For example, if the existing aggregated array-to-inverter ratio of 0.995 (see Table 1) can be further improved to 1.25, it is expected that the overall current THD will be improved as shown in Figure 5.

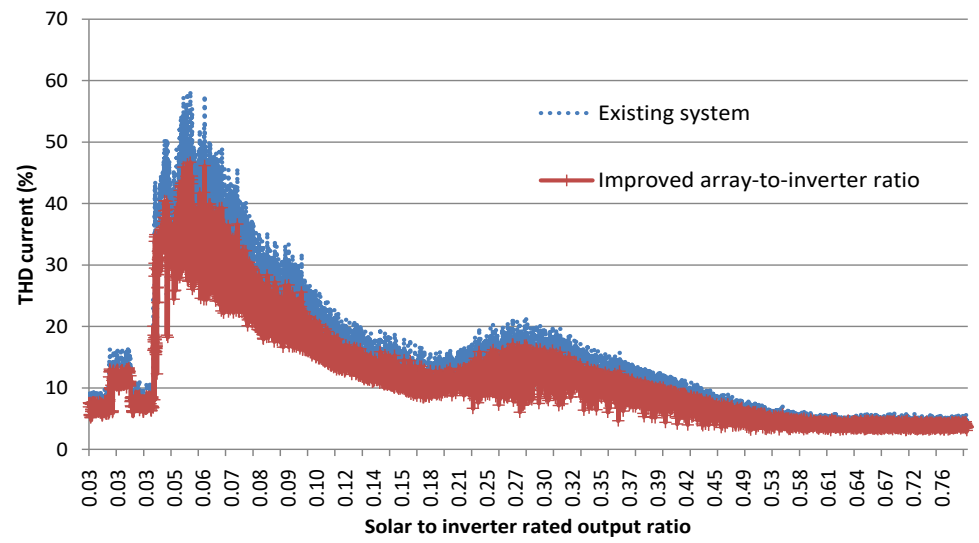

Figure 5. Total current harmonic distortion with improved array-to-inverter ratio

In addition, further analysis shows that the probability for the solar inverter to have the total current THD of less than 5\% is quite low. Figure 6 shows the probability of current THD measured for three representative solar days in Melaka, having the specific yield of 4.93, 4.33 and $3.09 \mathrm{kWh} / \mathrm{kWp}$, respectively. It can be observed from Figure 6 that the probability to achieve less than 5\% current THD in the UTeM gridconnected solar system is only $13 \%$. Approximately $67 \%$ of current THD were contributed by the current THD ranging from $6 \%$ to $20 \%$. It is also interesting to note that the cumulative probability of occurence for 
current THD of more than $20 \%$ is approximately $20 \%$ of the total occurence. Overall, in over $80 \%$ of the time, the total harmonic distortion for current measured at the point of common coupling is higher than $5 \%$.

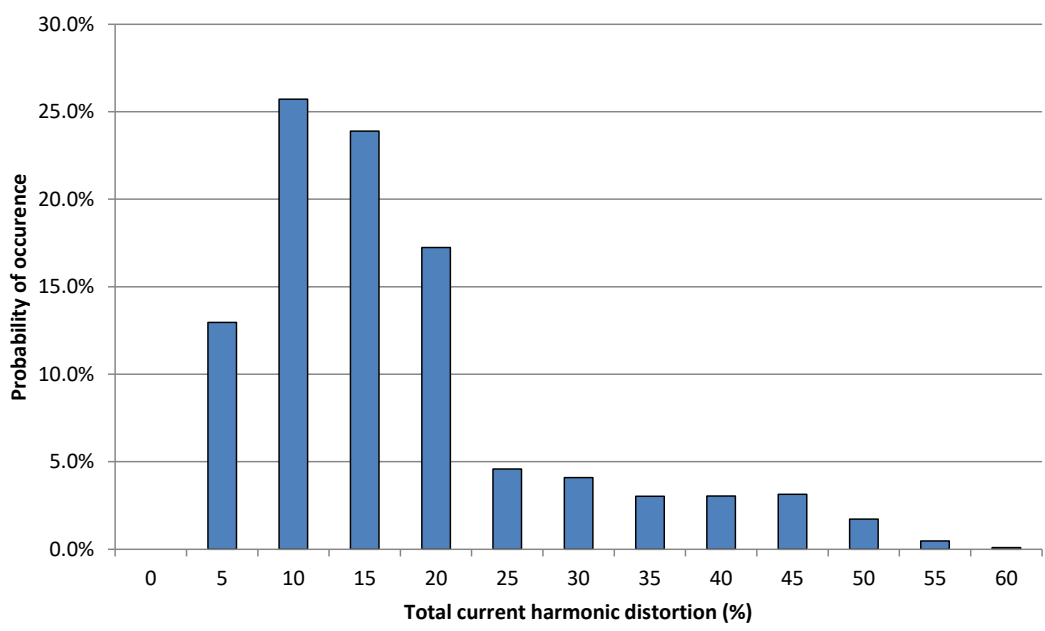

Figure 6. Probability of occurrence of THD for current

\section{CONCLUSION}

Actual field measurement has been carried out for a total of 12 single-phase solar system installed with different solar module technologies. The finding suggests the current quality from the inverter is highly dependent on the level of inverter output. Generally speaking, when the single-phase solar inverter output is at $50 \%$ or higher of its rated output, the performance current THD is less than $10 \%$. However, this value is still much higher than the requirement for solar system which is connected at medium voltage level. Hence, this paper suggests that the array-to-inverter ratio is one of the important solar PV system design criterias, which not only can improve overall system yields, but also increase the overall total harmonic distortion performance in the system.

\section{ACKNOWLEDGEMENTS}

The authors gratefully acknowledge the financial support provided by Universiti Teknikal Malaysia Melaka under the Research Grant: PJP/2016/FKE/HI5/S01482.

\section{REFERENCES}

[1] SEDA Malaysia Annual Report 2016.

[2] Nick Jenkins, Nicholas Jenkins, Ron Allan, Peter Crossley, Daniel Kirschen, David Kirschen, Goran Strbac, Embedded Generation, IET, 2000.

[3] K. M. Alawasa and A. I. Al-Odienat, "Power quality characteristics of residential grid-connected inverter ofphotovoltaic solar system," 2017 IEEE 6th International Conference on Renewable Energy Research and Applications (ICRERA), San Diego, CA, 2017, pp. 1097-1101.

[4] M. Ayub, C. K. Gan and A. F. A. Kadir, "The impact of grid-connected PV systems on Harmonic Distortion," 2014 IEEE Innovative Smart Grid Technologies - Asia (ISGT ASIA), Kuala Lumpur, 2014, pp. 669-674.

[5] F. Batrinu, G. Chicco, J. Schlabbach and F. Spertino, "Impacts of grid-connected photovoltaic plant operation on the harmonic distortion," MELECON 2006 - 2006 IEEE Mediterranean Electrotechnical Conference, Malaga, 2006, pp. 861-864.

[6] C. H. Tie, C. K. Gan, "Impact of grid-connected residential PV systems on the Malaysia low voltage distribution network," 2013 IEEE 7th International Power Engineering and Optimization Conference (PEOCO), pp. 670-675.

[7] S. V. S. Kumary, V. A. A. M. T. Oo, G. M. Shafiullah and A. Stojcevski, "Modelling and power quality analysis of a grid-connected solar PV system," 2014 Australasian Universities Power Engineering Conference (AUPEC), Perth, WA, 2014, pp. 1-6.

[8] S. Conti, S. Raiti and G. Tina, "Simulink modelling of LV photovoltaic grid-connected distributed generation," CIRED 2005 - 18th International Conference and Exhibition on Electricity Distribution, Turin, Italy, 2005, pp. 1-5.

[9] SEDA Malaysia, "Procedure for the Testing and Commissioning of Grid-connected Photovoltaic Systems in Malaysia" 2014

[10] SMA, Sunny Tripower Datasheet. 